Textures and Microstructures, 1988, Vols. 8 \& 9, pp. 457-466

Reprints available directly from the publisher

Photocopying permitted by license only

(C) 1988 Gordon and Breach Science Publishers Inc.

Printed in the United Kingdom

\title{
Applications of Neutron Diffraction Pole Figure Measurements on Polycrystalline and Monocrystalline Metallic Samples. Examples from the Four-circle Neutron Diffractometer in Jülich $\dagger$
}

\author{
W. SCHÄFER, S. HÖFLER and G. WILL \\ Mineralogisches Institut der Universität Bonn, Arbeitsgruppe \\ Neutronenbeugung in der KFA Jülich, Poppelsdorfer Schloß, D-5300 Bonn 1, \\ W. Germany
}

(Received July 17, 1987; in final form September 20, 1987)

\section{Dedicated to the memory of Professor Günter Wassermann}

Four different examples of neutron diffraction pole figure measurements are presented showing the variety of applications in metallic texture and microstructure analysis. Two examples are concerned with the study of texture effects on cold rolled titanium and warm bended $\alpha$-iron sheets. Two further examples are connected with the study of twinning laws and special orientation relationships in hexahedritic and octahedritic iron meteorites. Nishiyama-Wassermann orientations between $\alpha$ - and $\gamma$-iron phases are experimentally confirmed.

KEY WORDS: Neutron diffraction, pole figures, titanium, iron, meteorites, twinning.

$\dagger$ This work has been funded by the German Federal Minister for Research and Technology (BMFT) under the contract number 03-WI1BON. 


\section{INTRODUCTION}

The application of neutron diffraction extends the field of texture analyses. Compared with X-rays the analysis using neutrons has a number of specific advantages due to specific neutron characteristics (Kleinstück and Tobisch, 1968; Welch, 1986). Certainly the most important one is the high transmission (low absorption) of neutrons which offers the possibility to investigate large samples up to several $\mathrm{cm}$ in diameter, coarse grained material with grain sizes up to several $\mathrm{mm}$ and last but not least multiphase samples (Wenk et al., 1984; Höfler and Will, 1985). Further on, neutron diffraction allows one to investigate simultaneously crystallographic and magnetic textures (Will et al., 1986). As a consequence of the nuclear scattering lengths being independent of scattering angle pole figures of high indexed reflections can be easily introduced into texture analysis. Complete pole figures can be measured in transmission geometry on spherically formed samples without any absorption corrections (Tobisch and Bunge, 1972).

Neutron diffraction intensity pole figure measurements are an effective tool in texture and microstructure analysis. They cover the large field of studying different crystalline material properties or constitutions starting from preferred orientation of crystallites inside the volume of a polycrystalline sample, i.e. the texture in its true meaning, up to the orientation of large single crystals or fragments of single crystals with regard to the sample form. A further application is the study of twinning laws and special orientation relationships of different phases in originally mono-crystalline material.

The study of volume textures with neutrons, which contrast the $\mathrm{X}$-ray diffraction surface textures, has a wide field of application in geoscience and metallurgy (see e.g. Wenk, 1985; Wenk et al., 1986). In this paper we wish to point out the effectiveness of neutron diffraction pole figure measurements on metallic samples under two quite different aspects involving both poly- and monocrystalline material.

Although X-ray diffraction is predestined for the texture study of thin metal sheets, the exactness of complete X-ray pole figures is limited by the necessary corrections for the varying diffraction geometry. Therefore we have applied neutron diffraction for the evaluation of rolling or bending effects on the texture of titanium and $\alpha$-iron sheets.

A quite different metallurgical aspect is the study of twinning 
formations, martensitic transformations and different orientation relationships. Here we have applied neutron diffraction for the first time on several pieces of iron-nickel meteorites. Neutron diffraction is the only method to investigate fragments of single crystals of irregular form to study the entire volume without destroying precious pieces.

\section{EXPERIMENTAL}

The pole figure measurements were performed on the four-circle neutron diffractometer NANCY of Bonn University at the DIDO research reactor in Jülich using a neutron wavelength of $1.293 \AA$ from a $\mathrm{Cu}(111)$ monochromator (Höfler et al., 1986). The flux at the sample position is about $10^{6} \mathrm{n} / \mathrm{cm}^{2} \mathrm{~s}$; the monochromatic beam covers $20 \times 40 \mathrm{~mm}^{2}$. Divergence and size of the beam can be modified by a variable slit and collimator system.

Individual pole figures were measured in transmission geometry using a single $\mathrm{BF}_{3}$-tube positioned at the Bragg angle of the hkl reflection. The orientation dependent data collection was performed in a step scanning mode on concentric pole distances approaching an equal area scanning. The increments in azimuth $\Delta \varphi$ and in pole distance $\Delta \chi$ are preselectable according to the grain size of the polycrystalline material or the mosaic spread of the monocrystalline sample. The minimum possible step size is as low as $0.01^{\circ}$. The different scanning schedules for the texture investigation of the rolled metals and for the orientation relationships in the meteorites are summarized in Table 1. Background is subtracted from the pole figure intensities prior to the actual pole figure calculation. The background is determined from a $\theta-2 \theta$-scan preceding the pole figure measurements. The data are normalized and subsequently plotted as pole figures in stereographic projection.

\section{RESULTS FROM INDUSTRIAL METALLURGY}

\section{(a) Texture of cold rolled titanium sheets}

Cold rolled titanium sheets of 40,50 and $80 \%$ rolling degree have been provided from the Institut für Metallkunde und Metallphysik, 


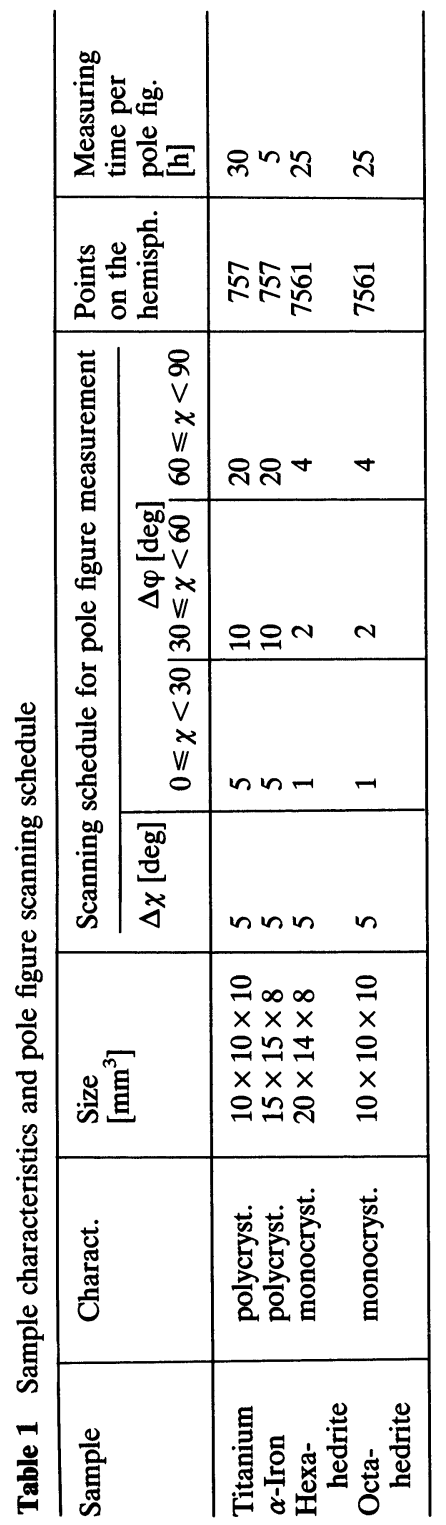



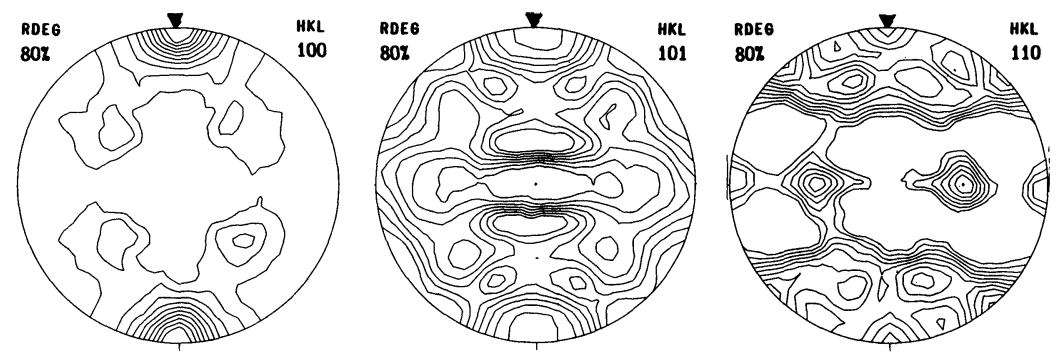

Figure 1100,101 and 110 pole figures of cold rolled titanium, rolling degree (rdeg) $80 \%$. The rolling direction is indicated by arrows. Maximum and minimum pole densities are 3.79 and 0.36 for $100,1.48$ and 0.48 for $101,1.84$ and 0.42 for 110 respectively.

Technische Universität Clausthal. The thickness of the metal sheets was about $1 \mathrm{~mm}$. For intensity reasons, cubical specimen have been prepared by stacking 10 sheets of $10 \times 10 \mathrm{~mm}^{2}$ cross section on top of each other. Araldite adhesive was used as a glue. Care was taken to ensure identical rolling direction of the individual sheets.

Intensities for the pole figures were collected for the most relevant reflections in hexagonal symmetry: 100, 002, 101 and 110 revealing distinct texture effects (Figure 1). The influence of the rolling degree is to be seen best by the 002 pole figures (Figure 2), which are characterized by three intensity maxima. Depending on the degree of rolling the central peak decreases at the expense of the two maxima at a pole distance of about $30^{\circ}$. The 100 planes are forced perpendicular to the rolling direction.
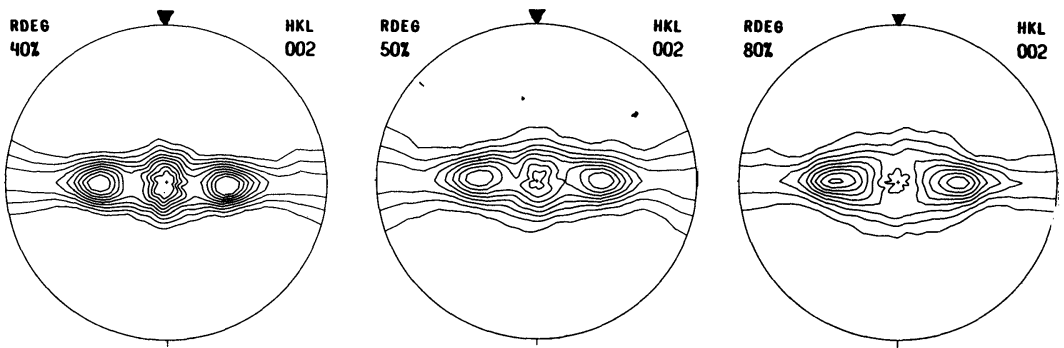

Figure 2002 pole figures of cold rolled titanium at different rolling degrees (rdeg): $40 \%$ (left), $50 \%$ (middle) and $80 \%$ (right). Maximum and minimum pole densities are 4.76 and 0.08 for $40 \%, 2.79$ and 0.45 for $50 \%, 4.14$ and 0.15 for $80 \%$ respectively. 


\section{(b) Texture of warm bended steel sheets}

Profiled steel sheets of $0.01 \mathrm{~mm}$ grain size have been provided from the Abteilung Maschinenbau, Fachgebiet Qualitätskontrolle, Universität Dortmund. Three different pieces of an U-profiled band originating from three different states during the rolling (2\% rolling degree) and warm bending process were analysed: piece (1) before rolling and bending, piece (2) after rolling and before bending and piece (3) after rolling and bending. For the pole figure measurements the specimen have been prepared by stacking 2 sheets $15 \times 15 \mathrm{~mm}^{2}$ and $4 \mathrm{~mm}$ thick. The deviation from spherical or cubical form was tolerated since only relative changes between the different states of machining should be studied. Due to the bcc structure of $\alpha$-iron pole figures were measured from the 110, 200, 211 and 310 reflections (Figure 3). For pieces (1) and (2) very weak
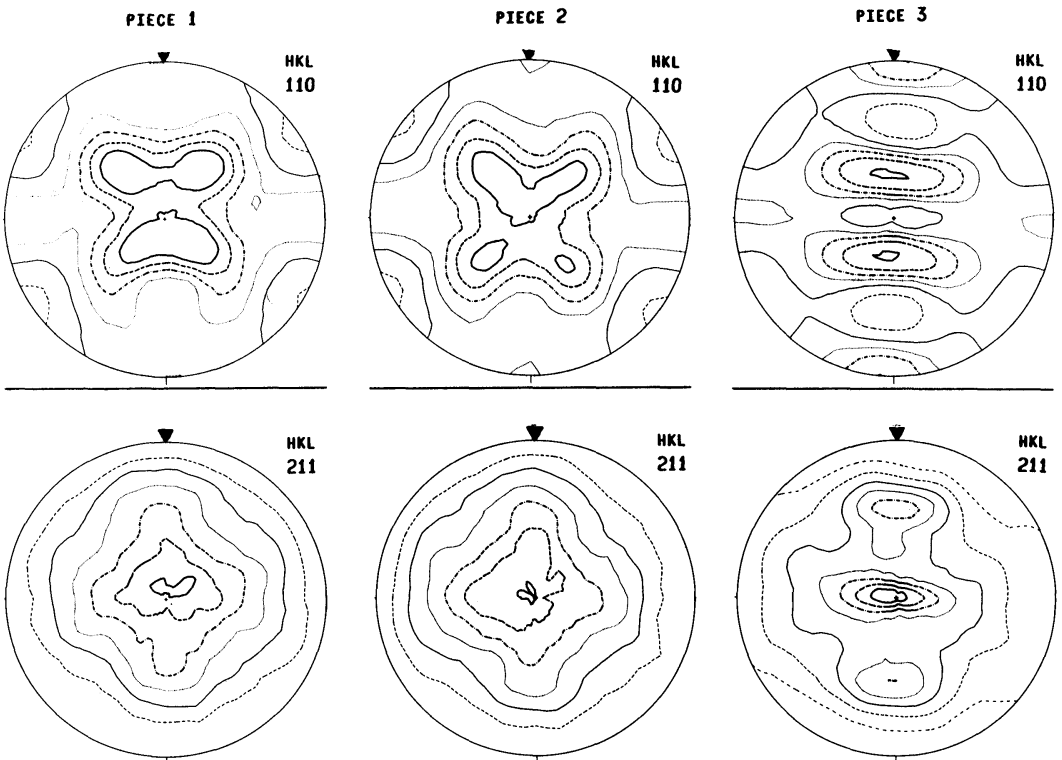

Figure 3110 (top) and 211 (bottom) pole figures of $\alpha$-iron for three different pieces of machining: before rolling and bending (left), after rolling and before bending (middle), after rolling and bending (right). Maximum and minimum pole densities for 110 are 1.34 and $0.67,1.30$ and $0.68,2.07$ and 0.47 respectively (going from left to right). The corresponding values for the 211 are 1.35 and $0.69,1.33$ and $0.68,1.72$ and 0.53 respectively. 
pole density maxima of only $1.3 \mathrm{mrd}$ are observed reflecting the fourfold symmetry of the sample form. While the rolling process between pieces .(1) and (2) reveals no texture effects pronounced modifications of the pole figure patterns are observed for piece (3) (see Figure 3) thus revealing distinct texture effects by the bending process of the material.

\section{RESULTS FROM METEORITES}

\section{(a) Twinning in hexahedritic iron meteorites}

Neutron diffraction investigations were made on two hexahedritic iron-nickel meteorites being composed of single crystals of kamacite, i.e. $(\alpha-\mathrm{Fe}, \mathrm{Ni})$ with a nickel content less than 6 weight $\% \mathrm{Ni}$. They are characterized by fine twin lamellae on $\{211\}$, the Neumann bands, over the entire meteorite. A sample fragment of about $20 \times 14 \times 8 \mathrm{~mm}^{3}$ was used for the pole figure measurements. The reflections 200, 110 and 211 were chosen for investigation and the results are shown in Figure 4. The meteorite originates from Coahuila, Mexico. It belongs to the museum of the Mineralogisches Institut der Universität Bonn.

All pole figures reveal sharp pole density peaks. Two kinds of pole maxima can be distinguished by intensity and extension. The extensive and high intensity peaks can easily be explained as face
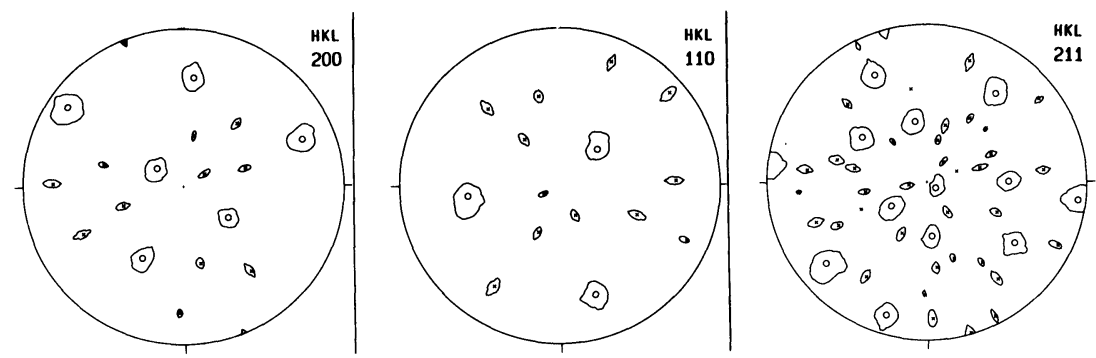

Figure 4200,110 and 211 pole figures of Coahuila meteorite. Maximum and minimum pole densities are 661.84 and 0.06 for $200,699.95$ and 0.01 for $110,294.56$ and 0.04 for 211 respectively. Single crystal and twin values differ roughly by a factor 100. Calculated pole sites of single crystal face poles are marked with o, calculated twin face pole sites with $x$. 
poles of a single crystal taking into account that a pole figure represents one hemisphere of the sample. The small peaks can be attached to the twins, whereby each single crystal face of the form $\{211\}$ represents a mirror plane for twinning. All resulting twins contribute to the pole figures. On the basis of the $\{211\}$-twinning law all experimentally detected intensity maxima of the Coahuila pole figures can be fitted by calculated pole sites, which are rotated from standard stereographic projection into the special and arbitrary orientation of the sample during the measurement (compare Figure 4).

\section{(b) Orientation relationships in octahedritic iron meteorites}

Octahedrites are iron-nickel meteorites with an octahedral arrangement of kamacite $(\alpha-\mathrm{Fe}, \mathrm{Ni})$ lamellae in an originally homogeneous $(\gamma-\mathrm{Fe}, \mathrm{Ni})$ single crystal. The lamellae are coated by taenite layers, i.e. $(\gamma-\mathrm{Fe}, \mathrm{Ni})$ with about 30 weight $\% \mathrm{Ni}$. Neutron diffraction pole figure measurements on a Gibeon/Namibia meteorite sample were performed to study the Widmanstätten structure of the orientation relationship between kamacite lamellae and taenite rims. The specimen was cube shaped and is part of a large meteorite plate belonging to the museum of the Mineralogisches Institut der Universität Bonn.

200 and 220 pole figures of fcc taenite and 200, 110 and 211 pole figures of bcc kamacite were measured (Figure 5). While the taenite

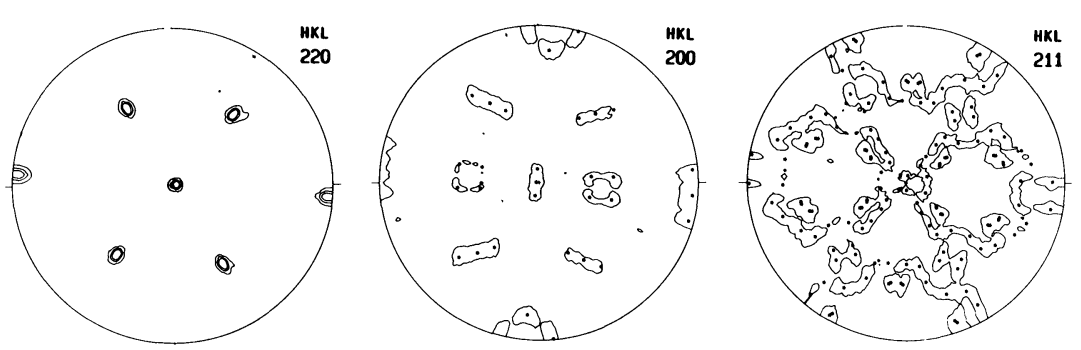

Figure 5 Pole figures of Gibeon meteorite; taenite 220 (left), kamacite 200 (middle) and 211 (right). Maximum and minimum pole densities are 43.37 and 0.27 for 220, 80.56 and 0.03 for $200,37.17$ and 0.01 for 211 respectively. For the kamacite pole figures calculated face poles of the Nishiyama-Wassermann orientation relationship are marked with *. 
patterns reveal several strong single pole density maxima, the kamacite pole figures are characterized by groups and bands with several intensity maxima. The taenite maxima can be attached to the face poles of a taenite single crystal. This indicates that all taenite rims exhibit the orientation of the parent $\gamma$-phase.

The orientation relationship between taenite and kamacite has been analysed according to Kurdjumov-Sachs (KS) (Kurdjumov and Sachs, 1930) and Nishiyama-Wassermann (NW) (Nishiyama, 1934; Wassermann, 1935) $\alpha-\gamma$ orientations. Rotating the calculated 100 poles of both relationships into the actual sample orientation deduced from the experimental taenite pole figures, the kamacite pole density maxima are fitted best by the NW-poles $\left(\{110\}_{\alpha}\left\|\{111\}_{\gamma},\langle 001\rangle_{\alpha}\right\|\langle\overline{1} 10\rangle_{\gamma}\right)$ (compare Figure 5). Calculated poles due to the KS relationship are found outside the experimental pole maxima.

\section{CONCLUSIONS}

Neutron diffraction has been used for quantitative texture analysis since about two decades (Bunge and Tobisch, 1968). It has experienced a lot of interest and a tremendous development in the last 6 years. Pole figure measurements can be performed successfully on a large variety of geological and also metallic samples without serious restrictions for crystalline constitution, sample size and sample form. The scanning procedure for sample orientations is adaptable to special circumstances of poly- or monocrystalline material. Depending on the grain size of the crystallites or on the mosaic distribution of individual single crystals the scanning pattern may be varied from stepwidths of several hundreds of a degree in the vicinity of narrow single crystal face poles up to five degrees or more for fine grained material.

Due to the large cross section of the monochromatic neutron beam with dimensions of several $\mathrm{cm}^{2}$ and due to the generally weak absorption of neutrons samples of several $\mathrm{cm}^{3}$ volume may be investigated. In case of thin metal sheets the relatively poor neutron intensity conditions can be overcome by stacking together several sheets. Thus, despite of artificially increased background by the glue or despite of even weak textures in the titanium and steel 
investigations presented here, neutron diffraction reveals reliable texture information on metals. It gives additional information that is not obtainable otherwise due to the restrictions in $\mathrm{X}$-ray texture analysis.

The study of iron meteorites by neutron diffraction pole figure measurements reported here for the first time is of basic interest not only in meteorite research, but also in metallurgical research. The mechanism of martensitic transformations for the $\alpha-\gamma$ iron phases in the meteorites run off by a diffusion controlled nucleation and growth process at extremely slow cooling. Besides the investigations of twinning and orientation relationships the neutron diffraction pole figures on the octahedrites revealed information on the phenomenon of variant selections indicating the presence of strain during kamacite growth (Höfler et al., 1988).

\section{References}

Bunge, H. J. and Tobisch, J. (1968). Z. Metallkunde 59, 471.

Höfler, S. and Will, G. (1985). Z. Krist. 170, 76.

Höfler, S., Schäfer, W. and Will, G. (1986). Experimental Techniques of Texture Analysis (ed. H. J. Bunge), DGM Informationsgesellschaft Verlag, Oberursel, pp. 241-251.

Höfler, S., Will, G. and Hamm, H.-M. Earth and Planetary Science Letters, to be published.

Kleinstück, K. and Tobisch, J. (1968). Kristall und Technik 3, 455.

Kurdjumov, G. and Sachs, G. (1930). Z. Physik 64, 325.

Nishiyama, Z. (1934). Science Rep. Tohuku Imp. Univ. Tokio 23, 637.

Tobisch, J. and Bunge, H. J. (1972). Texture 1, 125.

Wassermann, G. (1935). Mitt. K.-Wilh.-Inst. Eisenforschung 17, 149.

Welch, P. I. (1986). Experimental Techniques of Texture Analysis (ed. H. J. Bunge), DGM Informationsgesellschaft Verlag, Oberursel, pp. 183-216.

Wenk, H. R. (1985). Preferred Orientation in Deformed Metals and Rocks: An Introduction to Modern Texture Analysis, Academic Press, Orlando.

Wenk, H. R., Bunge, J., Jansen, E. and Pannetier, J. (1986). Tectonophysics 126, 271.

Wenk, H. R., Kern, H., Schäfer, W. and Will, G. (1984). J. Structural Geology 6, 687.

Will, G., Höfler, S. and Schäfer, W. (1986). Physica 136B, 473. 